\title{
Percepções dos discentes das graduações em Farmácia sobre o ensino de Homeopatia
}

\section{Perceptions of students graduations in pharmacy on teaching of Homeopathy}

\author{
Anderson Domingues Corrêa ${ }^{1}$ \\ Valéria Vieira ${ }^{2}$ \\ Sidnei Quezada Meireles Leite ${ }^{3}$ \\ Flávia Pinto Corrêa ${ }^{4}$
}

\section{RESUMO}

O objetivo desta pesquisa foi analisar o perfil do aluno do curso de farmácia, seus conhecimentos e expectativas a respeito da homeopatia durante a graduação, para que se possa proceder à criação coletiva de uma nova estrutura curricular. O estudo foi realizado com 300 alunos do curso de graduação em Farmácia das Universidades Federais do Rio de Janeiro (UFF e UFRJ). Aplicou-se um questionário contendo 16 perguntas, para um grupo de alunos do ciclo básico e outro grupo do ciclo profissional. Assim, foi possível formular propostas que melhor atendessem aos anseios dos estudantes, para uma possível abordagem dos conteúdos de homeopatia na graduação. Observou-se que os graduandos demonstraram interesse em conhecer mais sobre homeopatia. Para isso, sugeriram que uma disciplina de homeopatia deveria ser obrigatória na graduação. Além disso, constatou-se que os estudantes com maior conhecimento sobre a homeopatia acreditam mais em sua eficácia e, consequentemente, demonstraram interesse por se tornarem farmacêuticos homeopatas, ou, possuírem habilitação em homeopatia.

Palavras-chave: homeopatia; educação; currículo; farmácia.

\section{ABSTRACT}

The objective of this research has been to analyse the Pharmacy graduation student's profile, his/her knowledge and expectations about the homeopathy during graduation, so that the collective creation of a new curricular structure should be guaranteed. The study has been realized with 300 Pharmacy graduation students from Universidade Federal Fluminense and Universidade Federal do Rio de Janeiro (UFF and UFRJ). A questionnaire with 16 questions has been applied to two students groups: one from the basic cicle and the other from the professional cicle. Therefore, it has been possible to elaborate proposals that better reached the students desires for a possible approach of the homeopathy contents in the graduation. The results revealed that the graduation students showed interest in getting more knowledge about homeopathy. They believe that a homeopathy subject should be obligatory in the Pharmacy graduation course. Besides, the student who has knowledge about homeopathy thinks that it is efficient and consequentely enlarged the interest to become a homeopathy pharmacist or to have a homeopathy qualification.

Keywords: homeopathy; education; curriculum; pharmacy.

\footnotetext{
1 Instituto Federal de Educação Ciência e Tecnologia do Rio de Janeiro - IFRJ.

2 Instituto Federal de Educação Ciência e Tecnologia do Rio de Janeiro - IFRJ.

3 Instituto Federal de Educação Ciência e Tecnologia do Espírito Santo - IFES.

4 Instituto Oswaldo Cruz - Fiocruz.
} 


\section{INTRODUÇÃO}

A homeopatia foi introduzida no Brasil pelo médico francês Benoit Mure (1809-1858), que aportou no país em 1840 e, três anos mais tarde, já havia criado os primeiros estabelecimentos homeopáticos do Brasil, institutos para ensinar homeopatia, consultórios e farmácia (CORRÊA et all., 2006; CORRÊA e LEITE, 2008).

Entretanto, com a introdução dessa nova ciência, e, pelo motivo da farmacotécnica homeopática divergir da técnica de preparo dos medicamentos alopáticos, emergiu uma necessidade de mudança no ensino para os farmacêuticos. Desta forma, Corrêa e Quintas (1994), alegaram ser esta uma importante razão para que o ensino de homeopatia fosse ministrado como disciplina específica (CORRÊA e QUINTAS, 1994).

Reflexões sobre políticas curriculares, desde a publicação das Diretrizes Curriculares Nacionais do Curso de Graduação em Farmácia (Resolução CNE/CES 2/2002), onde foi expresso pelo documento a necessidade de que a formação do farmacêutico apresentasse um caráter generalista, trouxeram à tona uma urgência para que as faculdades repensassem suas práticas pedagógicas (MEC, 2002). Assim, o ensino de homeopatia voltou a ser debatido nas Faculdades de Farmácia.

Outro fator importante na consolidação da homeopatia foi a promulgação da "Política Nacional de Práticas Integrativas e Complementares no SUS” que propicia implantação da homeopatia em todos os níveis de atenção à saúde, com caráter multiprofissional; além de propor mecanismos de qualificação e divulgação dos conhecimentos básicos para profissionais de saúde, gestores e usuários. Incentiva a produção pública de medicamentos homeopáticos e fitoterápicos (BRASIL, 2006).

De acordo com reflexões de Macedo (2009), sobre política curricular, cadeias universalistas se utilizam de diversas estratégias para defender conteúdos tradicionalmente presentes, desta forma, resistências às mudanças sempre irão ocorrer, no intuito de preservar o domínio dos grupos hegemônicos.

Contudo, é sabido que, para que ocorra a produção do conhecimento é necessário rupturas de paradigmas, igualmente ocorre no ensino como um todo, e, especificamente no ensino farmacêutico. Mudanças na graduação de farmácia foram impostas pelo governo, necessitando que as faculdades estejam articuladas com essas propostas de formação generalista, humanista, crítica e reflexiva, para atuar em todos os níveis de atenção à saúde, com base no rigor científico e intelectual. O farmacêutico é capacitado ao exercício de atividades referentes aos fármacos e aos medicamentos, às análises clínicas e toxicológicas e ao controle, produção e análise de alimentos, pautado em princípios éticos e na compreensão da realidade social, cultural e econômica do seu meio, dirigindo sua atuação para a transformação da realidade em benefício da sociedade (MEC, 2002).

Deste modo, é importante estimular um trabalho de criação coletiva de uma nova estrutura curricular, em que a participação do aluno seja garantida e suas expectativas sejam analisadas e articuladas ao perfil de cada instituição.

Com o objetivo de inserir o aluno na discussão curricular, mais especificamente para o caso do ensino de homeopatia, esta pesquisa analisou o perfil do aluno, seus conhecimentos e suas expectativas sobre a homeopatia durante a graduação. Em uma revisão bibliográfica a respeito da percepção dos graduandos da área de saúde a respeito de homeopatia, foram encontrados trabalhos principalmente nas graduações de enfermagem e medicina, com menor representação, odontologia e farmácia, os quais alguns dados são brevemente comentados a seguir.

\subsection{Enfermagem}

A percepção dos alunos sobre a homeopatia foi pesquisada no curso de enfermagem através de um estudo com 178 acadêmicos, a respeito do conhecimento sobre terapias alternativas/complementares (TAC). Tal pesquisa constatou que $88 \%$ (157) dos alunos conheciam algum tipo, nesse grupo, apenas 31\% conheciam a homeopa- 
tia e 25\% dos alunos relataram fazer uso de homeopatia. Os alunos conheceram as TAC principalmente por meio do senso comum (veículos de comunicação e informações transmitidas verbalmente), tendo em vista que esse conhecimento não faz parte do "saber oficial” do aluno de enfermagem. Quando questionados se recomendariam o uso de TAC, 85\% responderam afirmativamente, e, a maioria (62\%) justificou essa indicação baseada na sua eficácia ou por vivenciar bons resultados com o seu uso. As autoras concluíram o trabalho, afirmando ser necessário o esclarecimento sobre TAC aos alunos dentro da faculdade, para que eles possam se interessar pela área, realizar cursos de atualização e incorporar as TAC no cuidado de enfermagem (TROVO et al., 2003).

Apesar do interesse crescente da enfermagem pelas Terapias Alternativas e Complementares há a necessidade de maior conhecimento e compreensão a respeito de sua inserção na prática da enfermagem (BARROS e ADAMS, 2005; BARROS e NUNES, 2006).

\section{2 Medicina}

A homeopatia foi reconhecida como uma especialidade médica pelo Conselho Federal de Medicina em 1980 e desde 1982, a questão do Ensino de Homeopatia vem sendo debatido, principalmente no que diz respeito à formação do médico, ao estímulo de um raciocínio holístico na compreensão do complexo fenômeno do adoecimento humano, ao estreitamento da relação médico-paciente (TEIXEIRA, 2006). Muitos médicos não deixam a medicina convencional para serem homeopatas, mas agregam a homeopatia ao seu arsenal terapêutico (ADLER et all., 2010). Diversos autores apresentam sugestões sobre a maneira de se ensinar homeopatia nas especializações médicas, defendendo a unificação e uniformização do ensino de homeopatia, reconhecendo-a como prática útil para a formação do futuro profissional (LINHARES, 1982; OLIVEIRA, 1982; OLIVEIRA, 1983; TUCUNDUVA NETO, 1983; EVANGELISTA, 2011).

Um estudo realizado com 51 estudantes de medicina presentes no XXXV Congresso Brasileiro de Educação Médica, em 1997, que teve como objetivo identificar as atitudes de estudantes em relação à acupuntura, fitoterapia, hipnose e homeopatia. Nesse estudo observou-se que quase todos os entrevistados sugeriram que a homeopatia fosse oferecida como disciplina nas escolas médicas brasileiras - 88\% julgaram que devesse ser de forma optativa, $10 \%$ de forma obrigatória e para $2 \%$ não deveria ser oferecida. Apenas $12 \%$ dos alunos relataram estar bem informados sobre a homeopatia, a mais conhecida das quatro práticas médicas heterodoxas entre os estudantes. Em relação à eficácia, $61 \%$ dos estudantes a consideraram bastante ou extremamente eficaz. A homeopatia foi a terapia mais utilizada (51\%) e 55\% dos entrevistados tinham interesse em conhecer melhor a homeopatia (DANTAS e RIBEIRO, 2002).

Em uma pesquisa mais longa e com maior amostragem, realizada com 395 médicos homeopatas, em duas fases (em 1998 com 110 médicos e em 2000 e 2001 com 275 médicos), identificou-se que as principais motivações que levaram os médicos a buscarem a especialização em homeopatia foram: insatisfação com a sua prática médica (35\%), insatisfação com a abordagem de doença pela alopatia (31\%), e, observação de resultados positivos obtidos pela homeopatia (30\%). A procura pela especialização visava buscar conhecimentos que não são adquiridos na graduação. Conhecer a homeopatia foi um fator crucial para a busca da especialização e ocorreu por meio do contato com colegas homeopatas, parentes em tratamento, ou por experiência pessoal com um tratamento homeopático (SALLES, 2005).

Em um estudo realizado no ano de 2002, com 484 graduandos da Faculdade de Medicina da Universidade de São Paulo (FMUSP), tendo por objetivo pesquisar as atitudes dos acadêmicos em relação ao ensino da homeopatia e da acupuntura, observou-se que $85,7 \%$ dos estudantes eram a favor da inclusão do ensino de homeopatia na matriz curricular dos cursos de medicina, sendo que $70,6 \%$ desse total acharam que devesse ser de forma optativa e $15,1 \%$, de forma obrigatória. A maioria dos estudantes (83,7\%) relatou possuir nenhum ou pouco conhecimento sobre homeopatia, 44,4\% demonstraram interesse em aprender mais sobre o assunto e somente 24,5\% acreditavam que a homeopatia é muito eficaz (TEIXEIRA et all., 2004; TEIXEIRA et all., 2005). Corroborando com esses resultados sobre a importância da obrigatoriedade da homeopatia na matriz curricular 
do curso de Medicina, um estudo de Fernandes e colaboradores (2011), apresentou esse reconhecimento por parte dos estudantes que já têm a incluída no currículo, desde 1999. Os autores realizaram um estudo com 196 estudantes de uma universidade Federal do Rio de Janeiro, do $5^{0}$ Período de Medicina, no ano de 2008. Neste, um total de 55,3\% consideraram importante sua obrigatoriedade na matriz curricular.

Outro exemplo de estudo, com o objetivo de mensurar a desinformação em relação à homeopatia, teve como amostra dezoito estudantes de Medicina participantes do $33^{\circ}$ Encontro Científico de Estudantes de Medicina - São Paulo - 2003. Nele, foi revelado que $43 \%$ dos estudantes não tinham conhecimento de que a homeopatia é uma "especialidade médica"; $100 \%$ desconheciam o fato do serviço de homeopatia estar presente em serviços públicos de saúde; $64 \%$ desconheciam sua inclusão no currículo de algumas faculdades de Medicina; e, todos os alunos se mostraram bastantes interessados em aprendê-la, na forma de disciplina obrigatória (64\%) ou optativa (36\%). Sugeriu-se, portanto, que a informação acerca dos aspectos fundamentais da homeopatia fosse transmitida nos primeiros anos da graduação médica (TEIXEIRA, 2007).

\section{3 Farmácia}

Numa pesquisa que associa as percepções dos estudantes dos cursos de Farmácia, Medicina e Odontologia, tendo por fundamento a teoria das representações sociais, observa-se que os graduandos de Farmácia são os usuários de homeopatia em maior número, apesar de ainda serem poucos na totalidade dos resultados, com 13,2\% dos alunos dos três cursos, sendo 9,4\% dos graduandos em Farmácia (Loch-Neckel et all., 2010). Ainda a respeito desse estudo, que objetivou investigar as percepções dos estudantes sobre homeopatia, os autores apontam que, 36,1\% dos entrevistados atribuíram á homeopatia a representação de que se trata de uma terapia que utiliza produtos naturais. Não dissociando nestes resultados, os alunos de Farmácia dos demais (Ibdem).

\section{PROCEDIMENTOS METODOLÓGICOS}

Trata-se de uma pesquisa de caráter exploratório descritivo, com abordagem qualitativa, analisada sob a ótica da triangulação, apoiada em observações e dados coletados ao longo da pesquisa com os sujeitos envolvidos (SOUSA, 2005).

A pesquisa teve como instrumento de coleta de dados um questionário contendo 16 perguntas abertas e fechadas, para um grupo de alunos do ciclo básico e outro grupo do ciclo profissional do curso de Farmácia das Universidades Federais do Rio de Janeiro.

A escolha das Faculdades de Farmácia da Universidade Federal Fluminense (UFF) e da Universidade Federal do Rio de Janeiro (UFRJ), como casos a serem analisados, deve-se ao fato de que, em suas propostas curriculares, a homeopatia figura como disciplina optativa. Sugere-se como explicação o fato de serem cursos tradicionais, com mais de cem anos de existência, e possuírem maior complexidade para promoverem e implementarem mudanças curriculares.

O estudo foi realizado com 300 alunos da graduação em Farmácia da UFRJ e da UFF. Do total, 74\% (222) dos participantes eram do sexo feminino e 26 \% (78) do sexo masculino. A idade média foi de 22 anos e eles já se encontravam, em média, há 2,8 anos na faculdade. A amostragem foi realizada com 37,4 \% (112) dos alunos do curso de Farmácia da UFF e 62,6 \% (188) dos alunos do curso de Farmácia da UFRJ.

A amostragem teve como princípio a coleta de dados, a partir de um grupo de alunos que estivesse no início do curso (Ciclo Básico) e outro que estivesse nos últimos períodos (Ciclo Profissional). O método foi baseado no Sistema de Avaliação do Ensino Superior (MEC, 2004). Desta forma, foi possível analisar a evolução das percepções dos alunos sobre o ensino de homeopatia, ao longo dos cursos de Farmácia, oferecidos nas respectivas Instituições Federais de Ensino Superior. No ciclo profissional, foram escolhidos três períodos, a partir 
do período inicial da formação profissional que, na UFRJ, inicia-se no quinto período, enquanto na UFF inicia-se no sexto período. $\mathrm{O}$ aluno da UFRJ pode optar pela disciplina de homeopatia a partir do $6^{\circ}$ período, enquanto na UFF, o aluno pode optar pela disciplina de homeopatia a partir do $7^{\circ}$ período.

O objetivo principal do questionário foi o de verificar quais as mudanças de interesses e percepções sobre a homeopatia os alunos vão apresentando ao longo dos anos, durante a graduação. Para isso, os questionários foram separados segundo o período cursado pelo aluno. Os alunos do início do curso foram descritos como Básico e os alunos dos últimos períodos (Ciclo Profissional), foram descritos como 1P, 2P e 3P, que representam, respectivamente, os alunos do primeiro, segundo e terceiro períodos do ciclo profissional (P).

Os dados obtidos com os questionários foram analisados à luz do referencial teórico da análise de conteúdo (BARDIN, 1988).

\section{RESULTADOS E DISCUSSÃO}

As duas Faculdades de Farmácia, embora sendo federais, apresentaram características diferentes com relação aos resultados dos questionários aplicados. Por exemplo, os alunos da UFF demonstraram maior interesse pela homeopatia nos parâmetros analisados, enquanto os alunos da UFRJ somente demonstraram que havia um interesse maior quando se perguntou sobre a obrigatoriedade da disciplina no curso.

Nos comentários feitos pelos alunos da UFF, a maior parte das preocupações foi inerente a se ter uma maior introdução de conteúdos de homeopatia nos currículos dos cursos de farmácia. Em relação aos estudantes da UFRJ, estes se preocuparam muito mais com a falta de comprovação científica da homeopatia e relataram o pouco contato que eles têm com conteúdos de homeopatia na faculdade sem, no entanto, sugerirem uma maior introdução desses conteúdos nos currículos.

\section{1 Pretensão de se tornar um profissional homeopata}

Quando se perguntou sobre a formação profissional: "Você pretende se tornar um farmacêutico homeopata?” Observou-se nos resultados que 56,2\% dos alunos da UFF responderam afirmativamente, enquanto na UFRJ responderam afirmativamente apenas $25 \%$ dos alunos. Esse número variou de $9,1 \%$ para a turma de $7^{\circ}$ período da UFRJ (3P) a 76,5\% para a turma de $6^{\circ}$ período da UFF (1P). Já em relação à pergunta: "Gostaria de concluir a graduação com habilitação para trabalhar em farmácia homeopática?”, um total de 79,6\% dos alunos da UFF respondeu afirmativamente, enquanto na UFRJ, responderam afirmativamente $51,1 \%$ dos alunos. Nesse caso, o índice variou de $22,7 \%$ para a turma de $7^{\circ}$ período da UFRJ (3P) a 92,5\% para a turma de $7^{\circ}$ período da UFF (2P).

Essa diferença sugere que, provavelmente, os alunos interpretaram que ser farmacêutico homeopata significava somente atuar com homeopatia e, não que ter habilitação para trabalhar em farmácia homeopática seria uma ampliação de seu campo de atuação.

Na UFRJ, os alunos do ciclo básico demonstraram mais interesse pela homeopatia do que os alunos da UFF, porém, à medida que os períodos avançam, os alunos da UFF vão apresentando maior interesse, enquanto os alunos da UFRJ há diminuição desse interesse (Figura 1). 
Figura 1 - Respostas, em percentual, obtidas dos alunos da UFRJ e da UFF, dos Ciclos Básico e Profissional, quando foi perguntado se eles pretendiam obter a habilitação de farmacêutico homeopata.

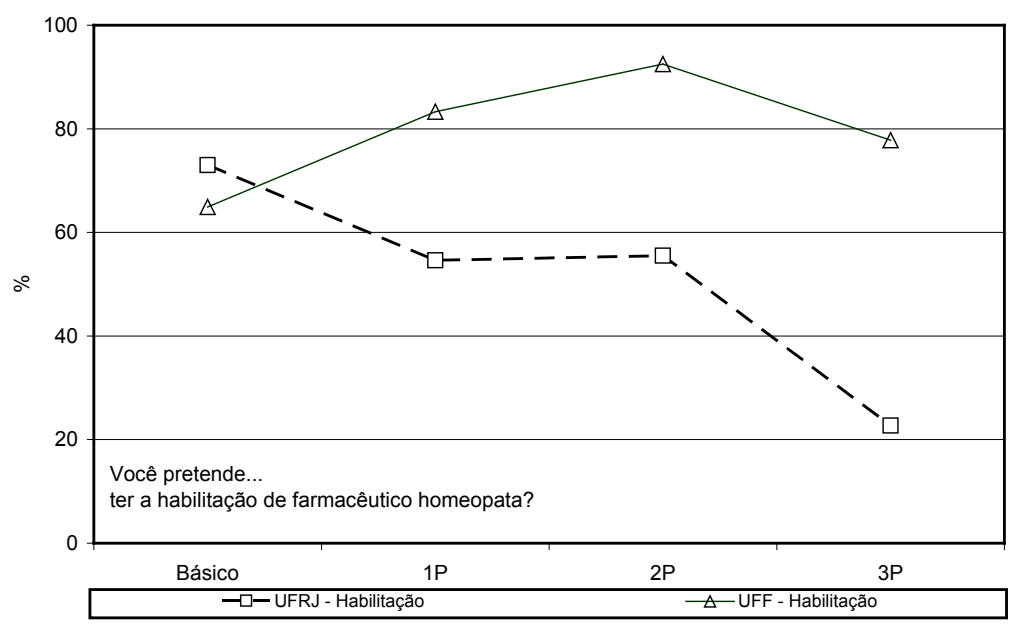

Fonte: dos autores.

\section{2 Conhecimento sobre homeopatia}

Com o objetivo de verificar o conhecimento básico de homeopatia, foi feita uma pergunta sobre a definição de homeopatia.

Nas respostas transcritas a seguir, pôde-se observar que os alunos comentaram o pouco conhecimento que têm nessa área e a pouca vivência que a faculdade propicia.

A homeopatia é muito pouco valorizada dentro da universidade, sendo evidente a falta de conheci-
mento dos alunos sobre o assunto... Na graduação, nada sabemos sobre os fundamentos da homeopatia.

A análise dos resultados demonstrou que os alunos da UFRJ obtiveram menor grau de acerto do que os alunos da UFF. Na UFRJ, a média de acertos foi de 47,3 \%, enquanto na UFF, o percentual médio de acerto foi de 74,1\%. Por outro lado, foi feita uma pergunta com relação à auto-avaliação sobre o nível de conhecimento de homeopatia que o aluno julgava possuir no momento, que tinha como possíveis respostas: 1- pequeno ou nenhum; 2 - médio ou razoável; e 3 - grande. Neste item podemos sugerir que os alunos da UFRJ tenderam a superestimar seus conhecimentos, pois houve uma diferença de 56,8\% entre os alunos que responderam incorretamente a questão sobre “o que é a homeopatia” e os que julgaram ter conhecimento pequeno ou nenhum na auto-avaliação, enquanto o contrário percebeu-se nos os alunos da UFF que subestimaram seus conhecimentos.

Como era de se esperar, quanto maior era o tempo do aluno na Faculdade, maior era seu conhecimento sobre homeopatia. O nível de acertos dos alunos da UFF cresceu de 56,8 do ciclo básico até 94,4\% no 3P e, na UFRJ, de 16,2\% do ciclo básico até 54,5\% no 3P.

\section{3 Interesse pelo ensino de homeopatia na graduação}

Cabe citar que praticamente todos os alunos responderam que gostariam de saber mais sobre a homeopatia, sendo 97,3\% dos alunos da UFF e 92,0\% dos alunos da UFRJ. Isso demonstrou que, pelo menos, uma disciplina de homeopatia, de caráter introdutório, para permitir que todos os alunos conhecessem um pouco desse saber, deveria existir. Ademais, tendo em vista que se constitui em uma área de atuação do farmacêutico e 
que esse profissional deva estar apto a, pelo menos, esclarecer as dúvidas básicas dos pacientes, a disciplina de homeopatia deveria ser de caráter obrigatório.

Os comentários de alunos a seguir corroboram com as hipóteses anteriormente levantadas, a saber:

Acho que as faculdades deveriam dar mais ênfase à homeopatia para que os estudantes tivessem mais informações sobre essa área.

... penso que a disciplina de Introdução à Homeopatia poderia ser obrigatória, visto que, assim, os alunos que não conhecem esse tipo de tratamento passariam a conhecê-lo ...

Considero importante para um profissional conhecer durante a sua formação todas as possibilidades de sua profissão futura ...

Na Figura 2 estão apresentadas as respostas, em percentual, obtidas dos alunos da UFRJ e da UFF, dos Ciclos Básico e Profissional, quando foi perguntado sobre o desejo de saber mais sobre homeopatia e sobre se ter uma disciplina de homeopatia obrigatória na Matriz Curricular.

Figura 2 - Respostas, em percentual, obtidas dos alunos da UFRJ e da UFF, dos Ciclos

Básico e Profissional, quando foi perguntado sobre o desejo de saber mais sobre homeopatia e sobre se ter uma disciplina de homeopatia obrigatória na Matriz Curricular.

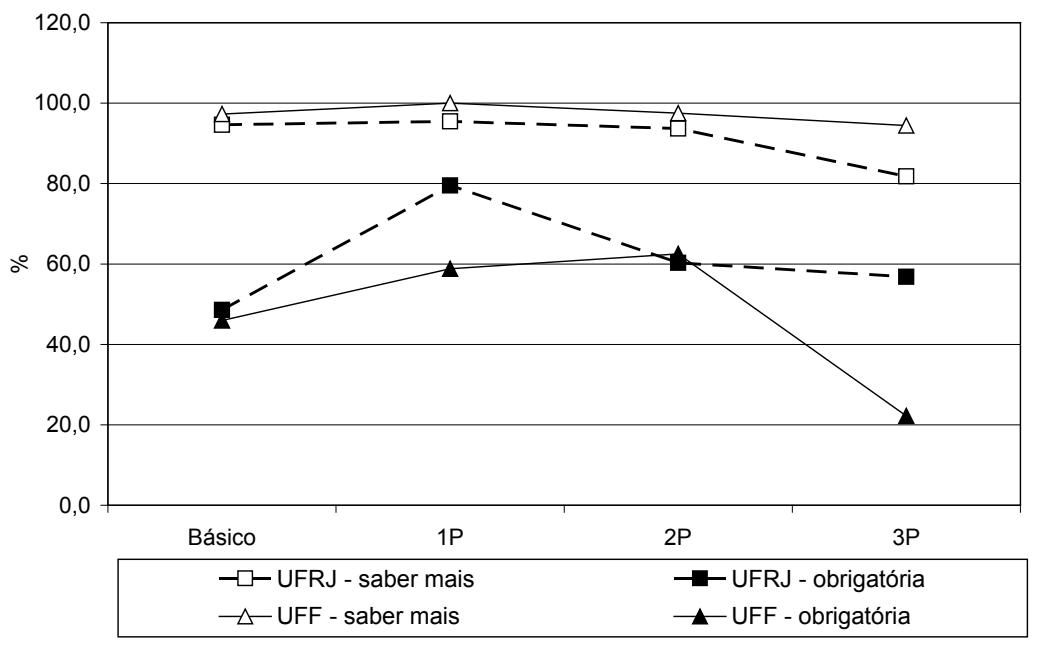

Fonte: dos autores.

Quando os alunos foram questionados sobre a obrigatoriedade da disciplina de homeopatia (Figura 2), 57,3 $\%$ do total de estudantes opinaram a favor da obrigatoriedade. Entretanto, em uma análise mais focalizada, esse índice variou de 79,5 \% para a turma de $5^{\circ}$ período da UFRJ (1P) a 22,2\% para a turma de $8^{\circ}$ período da UFF (3P). Esse dado se mostrou contraditório ao esperado, já que os alunos da UFRJ demonstraram menos interesse em obter a habilitação de farmacêutico homeopata e em trabalhar nessa profissão. Por outro lado, é possível que os alunos da UFF, que possuem um sistema de cumprimento da Matriz Curricular mais complexo, tendo que cursar 10 créditos de disciplinas optativas e eletivas, tenham pensado que, caso a disciplina de homeopatia se tornasse obrigatória, desfalcaria o quantitativo de disciplinas optativas e eletivas, comprometendo a sua vida escolar.

\section{4 Comentários dos professores sobre a homeopatia}

É comum ouvir dos alunos o relato de que os professores fazem mais citações sobre homeopatia à medida que os períodos avançam, porém, segundo eles, a quantidade de professores que fazem citações negativas também aumenta. Na UFRJ, os alunos relatam terem ouvido os professores falarem mais sobre a homeopatia do que 
os alunos da UFF. Em média, 68,1\% dos alunos da UFRJ ouviram algum professor falar sobre homeopatia, sem contar com o professor da disciplina específica de homeopatia e, desse total, 81,1 \% falaram em favor da homeopatia. Na UFF, 43,8 \% dos alunos ouviram algum professor falar sobre homeopatia, sem contar com o professor da disciplina específica de homeopatia e, desse total, 77,1 \% falaram em favor da homeopatia.

\section{5 Primeiro contato com a homeopatia}

Os alunos também foram questionados sobre como conheceram a homeopatia e as respostas sugeriram a divisão em grupos com distintas tendências: o grupo 1, cuja resposta foi "na própria família ou com pessoas que se tratam com homeopatia”: o grupo 2, cuja resposta foi (cursos extracurriculares e disciplinas curriculares) e o grupo 3, cuja resposta foi (leitura por conta própria e reportagens na televisão). Em relação ao avanço dos períodos, na UFRJ houve uma tendência ao crescimento desta afirmativa, enquanto na UFF o cenário permaneceu constante em relação à evolução dos períodos. O conhecimento da homeopatia por parte dos alunos foi crescente em relação ao avanço dos períodos no grupo 2, cuja resposta foi cursos extracurriculares e disciplinas curriculares. No grupo 3, cuja resposta foi leitura por conta própria e reportagens na televisão, o conhecimento da homeopatia foi crescente para os alunos da UFF, enquanto, para os alunos da UFRJ, foi decrescente.

\section{6 Tratamento homeopático}

Outro fato diferente foi a constatação de que, à medida que os períodos vão avançando, os alunos da UFF relatam, em maior proporção, que pelo menos um integrante da família já utilizou um tratamento homeopático. Entretanto, esse comportamento não foi observado nos alunos da UFRJ. É possível que esse fato esteja relacionado ao grau de conhecimento e a afinidade com a homeopatia que os alunos da UFF demonstram frente os alunos da UFRJ.

Com o decorrer do curso, os alunos da UFF relatam, em maior proporção, que os hospitais públicos deveriam oferecer tratamento e medicamento homeopáticos gratuitos. Na UFRJ há uma brusca queda em relação a este questionamento, da mesma forma que o interesse pela homeopatia diminui; de fato, os estudantes nem ao menos conseguem identificar os hospitais públicos como área de atuação para os farmacêuticos homeopatas.

\section{7 Eficácia do tratamento homeopático}

Quando se perguntou sobre a eficácia da homeopatia na atuação medicamentosa, na média, 75,6\% dos estudantes demonstraram acreditar que a homeopatia era eficaz (bastante ou extremamente). Houve variação de 40,9\% para a turma de $7^{\circ}$ período da UFRJ (3P) a 90\% para a turma de $7^{\circ}$ período da UFF (2P). Parece haver um leve crescimento de respostas positivas na avaliação sobre a eficácia da homeopatia por parte dos alunos da UFF, com o decorrer dos períodos, enquanto há um decréscimo dessas respostas por parte dos alunos da UFRJ.

\section{8 Triangulação dos resultados}

Durante a análise dos dados, observou-se que a percepção dos alunos quanto à eficácia da homeopatia estava diretamente relacionada a seu interesse profissional pela homeopatia, ou seja, os alunos que avaliaram a homeopatia como extremamente eficaz (E) possuíam maior interesse por ela do que os alunos que a avaliaram como bastante eficaz (B) e esses, por sua vez, possuíam maior interesse pela homeopatia do que os alunos que a avaliaram como pouco eficaz (P). Essa relação independe da fase que o aluno esteja na graduação, básico ou profissional. Assim, foi possível interpretar melhor alguns dados e concluir acerca do que fazer para motivar mais esses alunos a conhecerem a homeopatia. Em função disso, foi feita uma análise das respostas às perguntas do questionário baseado na percepção dos discentes em relação à eficácia da homeopatia. Para isso, os dados foram tabulados, dividindo-se em três grupos (Tabela 1), a saber: (E) para o grupo de alunos que avaliou a homeopatia como extremamente eficaz, (B) para o grupo de alunos que avaliou a homeopatia como bastante eficaz e (P) para o grupo de alunos que avaliou a homeopatia como pouco eficaz. 
A mesma análise, que foi realizada utilizando-se como parâmetro o ciclo do curso, também foi feita para algumas perguntas do questionário, só que em função da avaliação que os alunos fizeram sobre a eficácia da homeopatia.

O perfil do aluno que melhor avaliou a eficácia da homeopatia é aquele que teve um maior contato com a homeopatia, seja por ele ou integrantes da família terem utilizado tratamento homeopático ou por ter tido maior contato teórico com a homeopatia e, assim, ter obtido maior conhecimento na área.

Quanto melhor a avaliação da eficácia da homeopatia por parte dos alunos, maior o interesse em se tornarem farmacêuticos homeopatas e também em concluírem a graduação com habilitação em homeopatia.

Em relação à pergunta: “Gostaria de concluir a graduação com habilitação para trabalhar em farmácia homeopática?” um aluno respondeu negativamente e relatou que “Eu preciso de um pouco mais de conhecimento para optar, ainda não tive muito contato para saber”. Esse fato corrobora com o resultado da pesquisa e é mais um forte indício de que o aluno tem que conhecer melhor a homeopatia para poder se interessar em seguir seus estudos nesta área.

Os alunos que avaliaram a homeopatia como extremamente eficaz obtiveram o maior nível de acerto na questão “O que é homeopatia?” e fizeram as melhores auto-avaliações de seus conhecimentos, seguidos pelos que avaliaram a homeopatia como bastante eficaz; por fim, os alunos que avaliaram a homeopatia como pouco eficaz foram os que possuíam o menor conhecimento sobre a homeopatia.

Tabela 1 - Respostas às perguntas do questionário em função da percepção dos discentes em relação à eficácia da homeopatia (em percentual), onde $E$ = extremamente eficaz; $\mathbf{B}=$ bastante eficaz e $\mathbf{P}=$ pouco eficaz.

\begin{tabular}{lccccccc}
\hline \multicolumn{1}{c}{ PARÂMETROS } & & UFRJ & & UFF & & & \\
& & E & B & P & E & B & P \\
\hline Idade & anos/média & 21,8 & 21,4 & 23 & 21,7 & 22,2 & 22,7 \\
\hline Tempo de faculdade & média & 2,5 & 2,4 & 3,2 & 3,3 & 3 & 2,9 \\
\hline Pretende ser Homeopata & sim & 41,7 & 34,2 & 1,9 & 87,5 & 56,8 & 20,0 \\
\hline Conhecimento & médio/grande & 83,3 & 64,1 & 55,6 & 93,7 & 64,2 & 60,0 \\
\hline Saber mais & sim & 100 & 99,1 & 73,6 & 100,0 & 97,5 & 93,3 \\
\hline Disciplina & Obrigatória & 66,7 & 65,8 & 56,9 & 43,8 & 49,4 & 60,0 \\
\hline O que é Homeopatia & Semelhantes & 58,3 & 47 & 44,4 & 93,8 & 71,6 & 66,7 \\
\hline Como conheceu & Pacientes & 75,0 & 52,1 & 36,8 & 63,2 & 53,3 & 35,0 \\
\hline & Leitura & 8,3 & 14,8 & 22,1 & 0,0 & 10,9 & 15,0 \\
\hline Cursos & 8,3 & 12,7 & 13,2 & 31,6 & 9,8 & 10,0 \\
\hline Já se tratou & Disciplinas & 0,0 & 4,9 & 5,9 & 5,3 & 6,5 & 5,0 \\
\hline Hospitais públicos & TV & 8,3 & 13,4 & 20,6 & 0,0 & 15,2 & 25,0 \\
\hline Habilitação & outros & 0,0 & 2,1 & 1,5 & 0,0 & 4,3 & 10,0 \\
\hline
\end{tabular}

Fonte: dos autores. 


\section{CONSIDERAÇÕES FINAIS}

Os resultados indicam que quem tem maior conhecimento sobre a homeopatia acha que ela é eficaz e, consequentemente, apresenta maior interesse em tornar-se farmacêutico homeopata ou possuir habilitação em homeopatia. Portanto, uma disciplina de homeopatia optativa não serve para formar mais farmacêuticos homeopatas em número suficiente, uma vez que o aluno, não conhecendo a homeopatia, não terá interesse em fazer a disciplina. Foi o que encontramos na UFRJ, em que poucos alunos cursavam a disciplina optativa. Na UFF, uma disciplina como optativa funciona - ela é quase obrigatória - pois praticamente todos os alunos a cursam. Para que esse sucesso possa ocorrer são necessários investimentos na área, como por exemplo: a contratação de professores específicos para a área, uma farmácia universitária com manipulação homeopática, cursos extracurriculares, palestras, disciplinas introdutórias propedêuticas, como a Introdução à Farmácia, que abordem conteúdos de homeopatia, dentre outros. Esses dados são coerentes com o que é apresentado na literatura por Baracho et all. (2011), onde em pesquisa nos estados do Paraná e de Santa Catarina, observou-se que existe uma demanda por professores homeopatas capacitados.

Em uma pesquisa realizada com alunos da faculdade de medicina, foi identificada uma mudança de atitude dos alunos após a aquisição de um conhecimento cognitivo mínimo sobre a homeopatia. Este fato vem corroborar a hipótese aqui levantada, de que as pessoas que conhecem a homeopatia apresentam muito mais interesse pela área (TEIXEIRA, 2007).

Quanto mais eficaz o aluno julgou a homeopatia, menos ele a conheceu através de leitura por conta própria e reportagens na televisão. Na UFF, quanto mais eficaz o aluno considerar a homeopatia, mais ele conheceu a homeopatia por cursos extracurriculares e disciplinas curriculares. Neste grupo de respostas, o inverso ocorreu na UFRJ, (quanto mais eficaz o aluno avaliou a homeopatia, menos ele a conheceu por cursos extracurriculares e disciplinas curriculares) o que demonstra que estas estratégias, na UFRJ, não estão surtindo efeito e, portanto, as disciplinas curriculares, como por exemplo, a disciplina "Programa de Orientação Acadêmica I: introdução às ciências farmacêuticas" (que, durante o semestre, tem apenas uma aula de homeopatia com duas horas de duração) e os cursos extracurriculares realizados nas Semanas de Farmácia, anualmente, com nove horas de duração, devem ser repensados.

A partir da sugestão acima e após o conhecimento dos resultados do presente trabalho pelos professores da Faculdade de Farmácia da UFRJ, houve uma tentativa de inclusão da disciplina de homeopatia como obrigatória na nova matriz curricular; no entanto, este fato poderia ter atrasado ainda mais a implementação do novo currículo generalista que aguardou quatro anos por este ato. Assim, os professores de homeopatia conseguiram incluir, na disciplina de Farmacotécnica, um módulo, com duração de um semestre, sobre a homeopatia, o que resultou em uma grande procura pela disciplina optativa. Este fato vem corroborar a hipótese aqui levantada de que as pessoas que constroem um conhecimento correto sobre a homeopatia se interessam muito mais pela área.

A escolha das Faculdades de Farmácia da UFF e da UFRJ, como casos a serem analisados em relação às percepções dos discentes sobre o ensino de homeopatia, deve-se ao fato de que, em suas propostas curriculares, a homeopatia figura como disciplina optativa, bem como pelo fato de serem cursos tradicionais e possuírem maior complexidade para promoverem e implementarem mudanças curriculares. Um exemplo dessa complexidade é que a Faculdade de Farmácia da UFRJ demorou quatro anos, após o projeto ter sido aprovado na Congregação da Faculdade de Farmácia, para implementar o novo currículo de formação do farmacêutico generalista (CORRÊA e LEITE, 2008).

(...) realizar um trabalho de educação comparada sempre envolve tanto diferenças quanto semelhanças. Diferenças e semelhanças são oposições filosóficas, mas não são necessariamente antagônicas ou mutuamente exclusivas, nem na teoria nem na prática. Sistemas educacionais mostram diversidade em um aspecto e semelhanças em outro; a relação entre ambos pode ser mais complementar que antagônica (MARGINSON; e MOLLIS, 2001). 
Apesar das Faculdades de Farmácia da UFF e da UFRJ serem federais e oferecerem as disciplinas de homeopatia como optativas, a construção do conhecimento homeopático nessas instituições tem origens e trajetórias distintas. Na UFRJ, o destaque principal dos currículos parece ter estado mais voltado para a produção científica em áreas básicas e tecnológicas, e menos voltado para a promoção de saúde e seus problemas. Na UFF, o principal foco é a aplicação prática dos conhecimentos no âmbito dos serviços prestados à saúde da comunidade (CORRÊA e LEITE, 2008), por intermédio da manipulação de medicamentos homeopáticos, bem como a liderança na implantação da homeopatia no SUS e a coordenação do projeto "Homeopatia para Todos". Essas diferenças complementam a compreensão das características e das diferenças entre os dois processos de construção do conhecimento homeopático, bem como a situação atual das práticas nas duas Faculdades.

O fato de a Faculdade de Farmácia da UFRJ ter como característica uma produção científica considerável (CORRÊA e LEITE, 2008), aliado ao fato de ainda não ser conhecido o mecanismo de ação dos medicamentos homeopáticos, faz com que os alunos percam o interesse pela homeopatia ao longo do curso. Essa constatação pode indicar um caminho a seguir para encontrar um fator motivador para os alunos. Os professores de homeopatia deveriam mostrar-lhes que fazem pesquisas na área, além de descrever estudos científicos de outros pesquisadores. Essa estratégia deve ser utilizada em todas as oportunidades que os professores tiverem de falar sobre a homeopatia para os alunos, principalmente para os que ainda não conhecem a homeopatia, ou seja, na aula da disciplina optativa Introdução à Homeopatia, no curso Introdução à Homeopatia, oferecido na Semana de Farmácia da UFRJ e também na disciplina de Farmacotécnica Homeopática. Abaixo, alguns comentários dos alunos:

Apesar da aparente eficácia da homeopatia, não há resultados comprovados cientificamente.

Existe a necessidade de uma explicação melhor, ou mais aprofundada, por parte dos pesquisadores da área, sobre o que é homeopatia.

A homeopatia precisa de mais pesquisa e dados científicos para que alcance o respaldo necessário para a prática.

O interesse dos alunos da UFF pela homeopatia foi crescente ao transcorrer dos períodos, ao passo que na UFRJ ocorreu o inverso. Apesar dos alunos chegarem ao curso com maior interesse pela homeopatia, à medida que os conhecimentos foram avançando, ao longo dos períodos, esse interesse foi diminuindo. Uma possível elucidação para tal fato seria que a UFF está mais envolvida com a extensão, enquanto a UFRJ, com a pesquisa.

A inclusão de disciplinas de homeopatia nos currículos dos cursos de farmácia se mostra propícia, tendo em vista que (1) 93,7\% dos alunos demonstraram interesse em saber mais sobre a homeopatia, (2) 99\% dos alunos pensam que deveria haver uma disciplina na matriz curricular dos cursos de farmácia - 57,3\% de forma obrigatória e 41,7\% de forma optativa -, (3) 57,3\% tem conhecimento real da homeopatia e (4) 75,6\% avaliaram a homeopatia como sendo bastante ou extremamente eficaz, conforme apresentado na tabela 1 deste trabalho. 


\section{REFERÊNCIAS}

ADLER, U.C.; CÉSAR, A.T.; ADLER, M. S.; PADULA, A.E.; GAROZZO, E. N.; GALHARDI, W. M. P. Da padronização farmacêutica à pesquisa clinica: 20 anosde experiência com diluições cinquenta-milesimais. Revista Homeopatia. 73 (1/2): 57-67, 2010.

BARACHO, S. A. C.; DENEZ, K,. GAMARRA JUNIOR, J. S. Avaliação preliminar sobre o perfil do ensino de homeopatia nos cursos de Farmácia dos estados do Paraná e Santa Catarina. Int J High Dilution Res; 10(36):289291 Proceedings of the XXV GIRI Symposium and VIII CBFH; 2011 Sep 04-07; Foz do Iguaçu (Brazil), 2011.

BARDIN, L. Análise de conteúdo. Lisboa: Edições 70, 1988. 226 p.

BARROS, N. F.; ADAMS, J. A pesquisa sobre as terapias alternativas e complementares e enfermagem no Brasil. Rev. Latino-Am. Enfermagem, Ribeirão Preto, v. 13, n. 3, p. 453-4, 2005.

BARROS, N. F.; NUNES, E. D. Complementary and Alternative Medicine in Brazil: one concept, different meanings. Cad. Saúde Pública, Rio de Janeiro, v. 22, n. 10, p. 2023-8, 2006.

BRASIL. Ministério da Saúde. Secretaria de Atenção à Saúde. Departamento de Atenção Básica. Política Nacional de Práticas Integrativas e Complementares no SUS - PNPIC-SUS / Ministério da Saúde, Secretaria de Atenção à Saúde, Departamento de Atenção Básica. - Brasília: Ministério da Saúde, 2006. 92 p.

CORRÊA, A. D.; LEITE, S. Q. M. Ensino da homeopatia na graduação em farmácia: concepções e práticas pedagógicas em instituições do estado do Rio de Janeiro. Interface, Botucatu, v. 12, n. 25, p. 267-280, 2008.

CORRÊA, A. D.; QUINTAS, L. E. M. Princípios e conceitos atuais da medicina homeopática. Revista Brasileira de Medicina, Rio de Janeiro, v. 51, n. 7, p. 914-20, 1994.

CORRÊA, A. D.; SIQUEIRA-BATISTA, R.; QUINTAS, L. E. M. Similia Similibus Curentur: revisitando aspectos históricos da Homeopatia nove anos depois. Revista História, Ciências e Saúde - Manguinhos, Rio de Janeiro, v. 13, n. 1, p. 13-31, 2006.

DANTAS, F.; RIBEIRO, C. T. Atitudes de estudantes de medicina sobre práticas médicas heterodoxas no Brasil. Revista Brasileira Educação Médica, Rio de Janeiro, v. 26, n. 2, p. 99-104, 2002.

EVANGELISTA, O. P. Revista Homeopatia, XXX Congresso Brasileiro de Homeopatia, Atas, Comunicações Orais. 74 (3): 14, 2011.

FERNANDES, D. A. S.; FREITAS, F. J.; GUIMARÃES, G.M.; HAEGE, D.P. Revista Homeopatia, XXX Congresso Brasileiro de Homeopatia, Atas, Pôsteres. 74 (3): 131, 2011.

LINHARES, W. Ensino uniforme da homeopatia. Revista Homeopatia, São Paulo, n. 155, p. 22-6, 1982.

LOCH-NECKEL, G.; CARMIGNAN, F.;CREPALDI, M.A. A homeopatia no SUS na perspectiva de estudantes da área de saúde. Revista Brasileira Educação Médica, Rio de Janeiro, v. 34, n. 1, p. 82-90, 2010.

MACEDO, Elizabeth. Como a diferença passa do centro à margem nos currículos: o exemplo dos PCN. Educação \& Sociedade, Campinas, vol. 30, n. 106, p. 87-109, jan./abr. 2009.

MARGINSON, S.; MOLLIS, M. The door opens and the tiger leaps: theories and reflexivities of comparative education for a global millennium. Comparative Education Review, Chicago, v. 45, n. 4, p. 581-615, 2001.

MEC. Portaria $n^{\circ} 2.051$ de 9 de julho de 2004. Regulamenta os procedimentos de avaliação do Sistema Nacional de Avaliação da Educação Superior. Diário Oficial da União, 12 jul, 2004. 
MEC. Resolução CNE/CES n ${ }^{\circ} 2$ de 19 de fevereiro de 2002. Institui as Diretrizes Curriculares Nacionais do Curso de Graduação em Farmácia. Diário Oficial da União, 04 mar, 2002.

OLIVEIRA, F. D. Difusão e ensino da homeopatia no Brasil: uma visão estratégica. Revista Homeopatia, São Paulo, n. 155, p. 29-34, 1982.

OLIVEIRA, F. D. O ensino da homeopatia: pressupostos filosóficos. Revista Homeopatia, São Paulo, n. 159, p. 21-4, 1983.

SALLES, S. A. C. As Motivações dos Médicos para a Especialização em Homeopatia. Revista Brasileira Educação Médica, Rio de Janeiro, v. 29, n. 3, p. 167-73, 2005.

SOUSA, A. B. Investigação em Educação. Lisboa: Livros Horizonte, 2005. 412 p.

TEIXEIRA, M. Z. Homeopatia: Desinformação e Preconceito no Ensino Médico. Revista Brasileira Educação Médica, Rio de Janeiro, v. 31, n. 1, p. 15-20, 2007.

TEIXEIRA, M. Z. Homeopatia, ciência, filosofia e arte de curar. Revista Médica, São Paulo, abr - jun.; 85(2): 30-43, 2006.

TEIXEIRA, M. Z.; LIN, C. A.; MARTINS, M. A. Homeopathy and acupuncture teaching at Faculdade de Medicina da Universidade de São Paulo: the undergraduates’ attitudes. São Paulo Medical Journal, São Paulo, v. 123, n. 2, p. 77-82, 2005.

TEIXEIRA, M. Z.; LIN, C. A.; MARTINS, M. A. O Ensino de Práticas Não-Convencionais em Saúde nas Faculdades de Medicina: Panorama Mundial e Perspectivas Brasileiras. Revista Brasileira Educação Médica, Rio de Janeiro, v. 28, n. 1, p. 51-60, 2004.

TROVO, M. M.; SILVA, M. J. P.; LEÃO, E. R. Terapias alternativas/complementares no ensino público e privado: análise do conhecimento dos acadêmicos de enfermagem. Revista Latino-Am Enfermagem, Ribeirão Preto, v. 11, n. 4, p. 483-9, 2003.

TUCUNDUVA NETO, R. R. C. M. O ensino da homeopatia. Revista Homeopatia, São Paulo, n. 161, p. 12-5, 1983. 